\title{
Adherence to migraine treatment does not depend on the number of prescribed medications
}

\author{
A adesão ao tratamento da migrânea não depende do número de medicações prescritas \\ Ana Luisa C. Brasil Dozzaํ', Abouch Valenty Krymchantowski²
}

\begin{abstract}
Objective: To compare the adherence between monotherapy and politherapy in prophylactic migraine treatment. Method: Five hundred consecutive patients with migraine from a tertiary center were retrospectively studied as to the number of preventive medications prescribed during the first visit. Adherence, defined as returning for the next consultation after 4 to 6 weeks and following the prescribed regimens, were also evaluated and compared between patients. Results: 71.8\% were women, and 6\% of the patients did not receive any preventive medication, $11.4 \%$ received one drug, $22.2 \%$ two drugs, $41.4 \%$ three drugs, and $19 \%$ four drugs for the prevention of migraine. The overall adherence was $79.6 \%$. Respectively, 73.7, 71.8, 82.6 and $86.3 \%$ of those who received the prescription of one, two, three and four drugs returned, complying with the treatment. Conclusion: There is no difference in adherence to monotherapy or politherapy (one to four drugs) for the prophylaxis of migraine.
\end{abstract}

Key words: treatment, migraine, monotherapy, politherapy.

\section{RESUMO}

Objetivo: Comparar a adesão entre monoterapia e politerapia no tratamento profilático da migrânea. Método: Foram analisados retrospectivamente 500 pacientes com migrânea de um centro terciário, com vistas ao número de medicações preventivas prescritas na primeira consulta e adesão ao tratamento após 4 a 6 semanas. Resultados: $71,8 \%$ da amostra era composta de mulheres. Em relação ao tratamento preventivo da migrânea, 6\% não receberam medicação preventiva; 11,4\% receberam uma droga; 22,2\% duas drogas; 41,4\% três drogas e $19 \%$ quatro drogas. A adesão média foi de 79,6\%. Em relação à prescrição de uma, duas, três ou quatro drogas, essa adesão foi respectivamente de 73,7, 71,8, 82,6 e 86,3\%. Conclusão: Não houve diferenças na adesão à prescrição de medicações em monoterapia ou politerapia (uma a quatro drogas) para o tratamento preventivo da migrânea.

Palavras-Chave: tratamento, migrânea, monoterapia, politerapia.

Headache is one of the main reasons for visits to neurologists in Brazil and worldwide ${ }^{1,2}$. Migraine is the most prevalent type of headache in neurologic centers ${ }^{3}$. About 25 to $50 \%$ of the patients have shown adherence problems with prophylactic headache medications ${ }^{4,5}$. It decreases with regimens of more drugs and dosing. On the other hand, combining substances have been advocated for the treatment of migraine, especially for non-responsive patients $^{7-10}$. Therefore, the evaluation of the adherence to one or more drugs is an interesting issue in headache management.

The aim of this study is to compare adherence between monotherapy and politherapy (one to four drugs) in the prophylaxis of migraine in a tertiary center.

\section{METHODS}

We reviewed the medical records of 500 consecutive patients from a tertiary center located in the City of Rio de Janeiro, Brazil, who had been seen for initial consultation between January 2006 and January 2008. Only patients with migraine or chronic migraine or migraine and medication overuse headache $(\mathrm{MOH})$ were included. Demographic data, headache diagnosis, number of prophylactic medications prescribed at first visit and adherence defined by the returning for the next consultation after four to six weeks and the following to the prescribed medication regimens were collected 
and evaluated. In addition, all patients received a detailed headache diary during the first visit that assessed daily and symptomatic medication intake as well as headache severity and duration. Adherence, as expressed by complying with the prescribed medication in $\geq 80 \%$ of the days, which is a common operational definition of adequate medication adherence across a number of health conditions ${ }^{11-13}$, was evaluated by using a headache diary and a face-to-face interview during the follow-up consultation. It was compared between the patients taking one or more drugs as well. The headaches were classified according to International Classification of Headache Disorders (ICHD-II) ${ }^{14}$ and the ICHD-II appendix ${ }^{15}$ to classify chronic migraine and $\mathrm{MOH}$.

The Ethics Committee of Universidade Federal Fluminense approved the study. Statistics differences were analyzed using the Z-Test for proportions. In all analyses, $\mathrm{p}$ values less than 0.05 were considered significant.

\section{RESULTS}

Among the 500 patients, $71.8 \%$ were women. Ages ranged from 4 to 88 years (mean $38.7 \pm 14.7$ ). The peak prevalence was between 31 and 40 years either for women or men. The average headache duration was 20.2 years ( 0.1 to 80 years, standard deviation (SD) 13.4). The diagnoses were $48.5 \%$ episodic migraine without aura, $6.2 \%$ episodic migraine with aura, $7.3 \%$ chronic migraine and $38 \% \mathrm{MOH}$ and migraine.

The prophylactic treatment was prescribed to 470 (94\%) patients in the first visit. Thirty $(6 \%)$ of them did not receive preventive medication, $57(11.4 \%)$ received one drug, 111 (22.2\%) two drugs, 207 (41.4\%) three drugs and 95 (19\%) received an association of four preventive medications. The most prescribed combination of prophylactic medications, was a tricyclic antidepressant, a beta-blocker and flunarizine for 81 (16.2\%), followed by combination of a tricyclic antidepressant, a muscle relaxant and flunarizine for 74 (14.8\%). Sixty-two (12.4\%) patients received a tricyclic antidepressant, a beta-blocker, a muscle relaxant and flunarizine. The overall adherence was $79.6 \%(\mathrm{p}<0.001)$. Adherence to medications prescribed on monotherapy or in combination is showed in Figure. Comparison of adherence to different treatment regimens is depicted in Table.

\section{DISCUSSION}

The literature on adherence in headache treatment is scarce. The evidence available is consistent with the broader medical literature in chronic conditions indicating poor adherence to recommendations for acute and prophylactic medication use and appointment-keeping among headache patients $^{13}$. Between 25 and $50 \%$ of patients have been

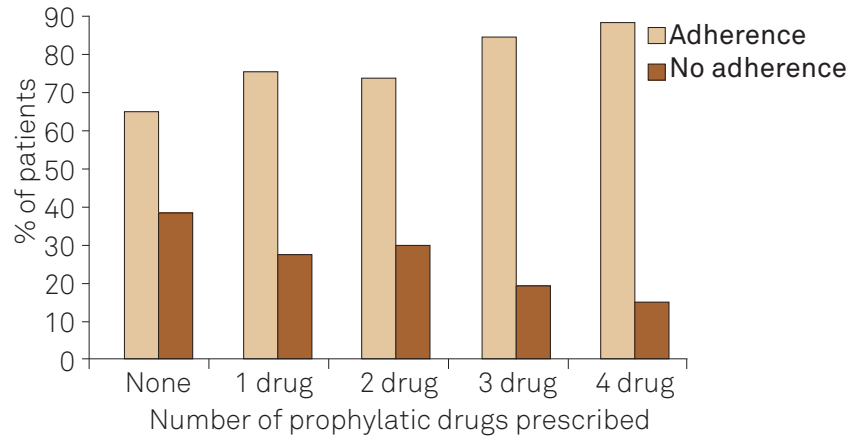

Figure. Correlation between adherence and number of prophylactic medication prescribed.

Table. Comparison of adherence to different treatment strategies.

\begin{tabular}{lcc} 
Treatment & Adherence (\%) & \multicolumn{2}{c}{ Treatments comparison } \\
1 drug & 73.7 & $\mathrm{~ns}^{1}$ \\
2 drugs & 71.8 & $\mathrm{~ns}$ \\
\hline 1 drug & 73.7 & $\mathrm{~ns}$ \\
3 drugs & 82.6 & $\mathrm{p}>0.05$ \\
\hline 1 drug & 73.7 & \\
4 drugs & 86.3 & $\mathrm{p}>0.05$ \\
\hline 2 drugs & 71.8 & $\mathrm{n}$ \\
3 drugs & 82.6 & \\
\hline 2 drugs & 71.8 & \\
4 drugs & 86.3 & \\
\hline 3 drugs & 82.6 & \\
4 drugs & 86.3 & \\
\hline
\end{tabular}

${ }^{1}$ Not statistically significant: $p>0.05$.

shown noncompliant with prophylactic headache medications $^{4,5}$. A large survey yielding data from 1,160 severe headache patients demonstrated that the most common reasons for not filling a prescription were high cost (33\%) and safety concerns $(30 \%)^{14}$.

Reports from Literature have demonstrated that compliance decreases with more frequent or complex dosing regimens ${ }^{4,6}$, however we did not find studies that correlate number of medications prescribed with adherence in the preventive treatment of headaches. By analyzing the table, one can observe that there is no statistical difference between adherence to treatments in monotherapy or in combination of medications, suggesting a rate even higher of adherence among those patients who received 3 or 4 drugs, when compared with those who received 2 drugs. It was different from our initial belief that prescribing more than one drug during the first visit could impair adherence, since tolerability and safety concerns would arise from wrong patient assumptions.

The overall adherence in our study was greater than that demonstrated in the literature ${ }^{4,5}$. Edmeads et al ${ }^{15}$ demonstrated that, after the initial consultation, $40 \%$ of patients did not return for the follow-up, and $24 \%$ dropped out later. Likewise, Spierings et $\mathrm{al}^{16}$ reported that $40.5 \%$ of patients did not comply with their recommendation for a follow-up treatment appointment after their initial consultation. 
Failure rates for appointment keeping range from 8 to $63 \%{ }^{16}$. Up to $50 \%$ of patients on chronic medical regimens drop out of care entirely within 1 year of beginning treatment ${ }^{20}$. In fact, adherence to prescribed drug dosing regimens declined with longer periods of follow-up ${ }^{21}$. Therefore, our findings may be due to the shorter period of follow-up compared with other studies. In addition, one might speculate that our difference in findings was due to the comprehensive approach that a specific tertiary center carries out and/or the type of patients who seek medical care in centers like ours, i.e., patients who already tried monotherapy in other treatment instances. We may assume that a better study design would have been a comparison between adherence in patients with and without previous treatment experiences.
Gaul et $\mathrm{al}^{22}$ showed $35 \%$ of prophylactic medication adherence after a follow-up of 12-18 months. This result is poorer than that achieved by Zeeberg et $\mathrm{al}^{23}$, whose patients show higher adherence (39\%) after a period of 7.8 months. This was not the case in the present study, with patients' follow-up only during the initial two consultations.

Therefore, in a headache tertiary center, most of the patients adhered to the initial treatment recommendations and no difference was found between the prescription of one or more drugs for migraine prophylaxis. Longer-term studies, as well as prospective ones, involving adherence to different medication regimens would clarify whether our findings are consistent with the daily clinical practice reality.

\section{References}

1. Hopkins A, Menken M, DeFrinse G. A record of patient encounters in neurological in practice in the United Kingdon. J Neurol Neurosurg Psychiatry 1989;52:436-438.

2. Bekkelund SI, Albretsen C. Evaluation o referrals toa department of neurology. J R Coll Physicians Lond 1996;30:426-431.

3. Gesztelyi G, Bereczki D. Primary headaches in an outpatient neurology headache clinic in East Hungary. Eur J Neurol 2004;11:389-395.

4. Mulleners WM, Whitmarsh TE, Steiner TJ. Noncompliance may render migraine prophylaxis useless, but once-daily regimens are better. Cephalalgia.1998;18:52-56.

5. Fitzpatrick RM, Hopkins AP. Effects of referral to a specialist for headache.J R Soc Med 1983;76:112-115.

6. Cramer JA, Scheyer RD, Mattson RH. Compliance declines between clinic visits. Arch Intern Med 1990;150:1509-1510.

7. Peroutka SJ. Beyond monotherapy: rational politherapy in migraine. Headache 1998;38:18-22.

8. Krymchantowski AV, Jevoux Cda C. Low-dose topiramate plus sodium divalproate for positive responders intolerant to full-dose monotherapy. Headache 2012;52:129-132.

9. Krymchantowski AV, Jevoux C da C, Bigal ME. Topiramate plus nortriptyline in the preventive treatment of migraine: a controlled study for nonresponders. J Headache Pain 2012;13:53-59.

10. Evans RW, Pascual J, Láinez MJA, Leira R. Bending the rule of monotherapy for migraine prevention? Headache 2005;45:748-750.

11. DiMatteo MR. Variations in patients' adherence to medication recommendations: A quantitative review of 50 years of research. Med Care 2004;42:200-209.

12. Osterberg L, Blaschke T. Adherence to medication. N Engl J Med 2005;353:487-497.

13. Donnan PT, MacDonald TM, Morris AP. The DARTS/MEMO collaboration: Adherence to prescribed oral hypoglycemic medication in a population of patients with type two diabetes: a retrospective study. Diabetes Med 2002;19:279-284.

14. Headache Classification Subcommittee of the International Headache Society. The International Classification of Headache Disorders, 2nd Edition. Cephalalgia 2004;24:1-160.
15. Olesen J, Bousser MG, Diener HC, et al., Headache Classification Committee. New appendix criteria open for a broader concept of chronic migraine. Cephalalgia 2006;26:742-746.

16. Dunbar-Jacob J, Erlen JA, Schlenk EA, Ryan CM, Sereika SM, Doswell WM. Adherence in chronic disease. Ann Rev Nurs Res 2000;18:48-90.

17. Gallagher RM, Kunkel R. Migraine medication attributes important for patient compliance: concernsabout side effects may delay treatment. Headache 2003;43:36-40.

18. Edmeads J, Findlay H, Tugwell P, Pryse-Phillips W, Nelson RF, Murray TJ. Impact of migraine and tension-type headache on life-style, consulting behaviour, and medication use: s Canadian population survey. Can J Neurol Sci 1993;20:131-137.

19. Spierings EL, Miree LF. Non-compliance with follow-up and improvement after treatment at a headache center. Headache 1993;33:205-209

20. Haynes RB, Dantes R. Patient compliance and the conduct and interpretations of therapeutic trials. Contr Clin Trials 1987;8:12-19.

21. Berger A, Bloudek LM, Varon SF, Oster G. Adherence with migraine prophylaxis in clinical practice. Pain Pract 2012;12:541-549.

22. Gaul C, van Doorn C, Webering N, et al. Clinical outcome of a headache-specific multidisciplinary treatment program and adherence to treatment recommendations in a tertiary headache center: an observational study. Headache Pain 2011;12:475-483.

23. Zeeberg P, Olesen J, Jensen R. Efficacy of multidisciplinary treatment in a tertiary referral headache centre. Cephalalgia 2005;25:1159-1167.

24. Berg J, Dunbar-Jacob J, Rohay JM. Compliance with inhaled medications: the relationship between diary and electronic monitor. Ann Behav Med 1998;20:36.

25. Garber MC, Nau DP, Erickson SR, Aikens JE, Lawrence JB. The concordance of self-report with other measures of medication adherence: a summary of the literature. Med Care 2004;42:649-652.

26. Stone AA, Shiffman S, Schwartz JE, Hufford MR. Patient noncompliance with paper diaries. BMJ 2002;324:1193-1194. 